\title{
Role and clinical course of verotoxigenic Escherichia coli infections in childhood acute diarrhoea in Argentina
}

\author{
Mariana Alejandra Rivero, ${ }^{1,2}$ Juan Antonio Passucci, ${ }^{2}$ \\ Edgardo Mario Rodriguez ${ }^{2}$ and Alberto Ernesto Parma ${ }^{1}$ \\ ${ }^{1}$ Área Inmunoquímica y Biotecnología, Departamento de Sanidad Animal y Medicina Preventiva, \\ Facultad de Ciencias Veterinarias, Universidad Nacional del Centro de la Provincia de Buenos \\ Aires, Pinto 399 (7000), Tandil, Argentina \\ ${ }^{2}$ Área Epidemiología y Estadística, Departamento de Sanidad Animal y Medicina Preventiva, \\ Facultad de Ciencias Veterinarias, Universidad Nacional del Centro de la Provincia de Buenos \\ Aires, Pinto 399 (7000), Tandil, Argentina
}

Correspondence

Mariana Alejandra Rivero

mrivero@vet.unicen.edu.ar

Received 28 August 2009

Accepted 16 October 2009
The aim of this study was to investigate the role and clinical course of verotoxigenic Escherichia coli (VTEC) infections in children with acute diarrhoea from Argentina, the country with the highest worldwide incidence of haemolytic uraemic syndrome (HUS). To accomplish this objective, 437 samples from children up to 6 years old with acute diarrhoea were collected and processed. More than $60 \%$ of the children studied presented watery or mucous diarrhoea without blood, and in $25.2 \%$ of the cases the samples contained blood. In a first screening, a multiplex PCR was performed to detect the presence of the $v t_{1}, v t_{2}$, eae, ehxA and saa virulence genes. The strains were then isolated and analysed to characterize their serotypes, virulence genes, antibiotic susceptibility profiles and verotoxin (VT) production. Forty-four of the 437 samples $(10.1 \%)$ were positive for VTEC virulence genes. VTEC-infected patients presented different types of diarrhoea (27.3\% belonged to the non-bloody type). Several serotypes and virulence genotypes were found. Isolates belonged to the serotypes $\mathrm{O} 157: \mathrm{H} 7, \mathrm{O} 145: \mathrm{H}^{-}, \mathrm{O} 26: \mathrm{H} 11, \mathrm{O} 121: \mathrm{H} 19, \mathrm{O} 111: \mathrm{H} 2$ and O118: H2. HUS developed in 16 (36.4\%) patients positive for VTEC virulence genes. All of the VTEC isolates produced a cytopathic effect on Vero cell monolayers, confirming the ability to express VT. Despite most strains being sensitive to all of the antimicrobials studied, a positive association between clinical progression to HUS and antibiotic therapy was observed for the total number of patients studied, as well as for the VTEC $^{+}$group. In conclusion, the data obtained in this study increase our knowledge of the role and clinical course of VTEC infection in childhood acute diarrhoea beyond bloody diarrhoea, and might be considered for the prevention, diagnosis and management of this disease. It is possible that the optimal approach for VTEC diagnosis could be using multiplex PCR to search for the presence of the $v t_{1}, v t_{2}$, eae and ehxA genes.

\section{INTRODUCTION}

Infection with verotoxigenic Escherichia coli (VTEC), also known as Shigatoxigenic E. coli, can cause a wide spectrum of clinical manifestations in humans, from asymptomatic infection, mild to moderate diarrhoea and haemorrhagic colitis to haemolytic uraemic syndrome (HUS) (Karmali, 1989; Proulx et al., 2001; Tarr et al., 2005). Watery diarrhoea develops in about $90 \%$ of infected children and in most cases becomes bloody. HUS progression is observed in approximately $5-15 \%$ of patients. There is no specific treatment for this infection (Karmali, 1989; Karch et al.,

Abbreviations: HUS, haemolytic uraemic syndrome; IMS, immunomagnetic separation; VT, verotoxin; VTEC, verotoxigenic Escherichia coli.
2005; Tarr et al., 2005; Goldwater, 2007). Therapy for VTEC infections with antibiotics or drugs that inhibit intestinal motility has been associated with an increased risk of developing HUS. Currently, treatment is only supportive, focusing on fluid and electrolyte management. Hospitalization during the diarrhoeal phase seems to benefit VTECpositive patients. Precocious treatment is an absolute requirement for success and depends on early diagnosis, making rapid diagnostic techniques necessary (Wong et al., 2000; Karch et al., 2005; Tarr et al., 2005; Goldwater, 2007).

E. coli $\mathrm{O} 157: \mathrm{H} 7$ has been reported to be the most common VTEC serotype involved in human disease. However, other VTEC serotypes can cause a similar disease spectrum (Griffin \& Tauxe, 1991; Karch et al., 2005; Tarr et al., 
2005). The virulence of VTEC is mainly determined by its ability to produce verotoxins (VTs), also called Shiga toxins. Most VTEC strains carry the gene encoding VT2 $\left(v t_{2}\right)$ and about two-thirds carry that encoding VT1 $\left(v t_{1}\right)$ (Karmali, 1989; Proulx et al., 2001; Tarr et al., 2005). Other virulence factors, pathogenic for human hosts, have been described: intimin (eae), by which E. coli mediates intimate attachment to epithelial cells, enterohaemolysin $(e h x A)$ and an autoagglutinating adhesion factor called Saa (saa), associated with eae-negative Shigatoxigenic E. coli (Paton \& Paton, 1998; Paton et al., 2001; Tarr et al., 2005).

Argentina has the highest worldwide incidence of reported HUS cases in children aged 5 years or under, with HUS being the major cause of acute renal failure and the second leading cause of chronic renal failure and renal transplantation in children. Currently, the mortality rate among children with this syndrome is about $5 \%$. However, routine microbiological detection of VTEC in stools from diarrhoeic children is not currently carried out. Only in some cases of bloody faeces is the search oriented towards detection of the O157 serogroup (Voyer, 1996; López et al., 1998; Rivero et al., 2004; Rivas et al., 2006). Few studies have been performed to evaluate the role of VTEC infection in children with acute diarrhoea in Argentina. One such study, performed by López et al. (1998), included HUS patients, patients with grossly bloody diarrhoea, patients with watery diarrhoea and healthy children.

There are few studies on the clinical spectrum caused by VTEC infection in children in Argentina. Information on VTEC epidemiology in children with acute diarrhoea, particularly in the watery phase without blood, is also lacking. An early diagnosis, essential for establishing timely treatment and preventative measures, is not available for the general population. Hence, the present work was performed to study the role of VTEC infections in childhood acute diarrhoea, to generate information useful in the prevention, diagnosis and clinical management of the disease.

\section{METHODS}

Samples. Between December 2002 and April 2009, 437 children up to 6 years old with acute diarrhoea were included in the study. Acute diarrhoea was defined clinically as any sudden and significant increase in the frequency or decrease in the consistency of stools lasting less than 2 weeks. Stool samples from each patient were identified by a numeric code and placed in a transport medium. The enrolled patients had attended public or private healthcare institutions, including hospitals and clinics, in the cities of Tandil and its surroundings, Bahía Blanca, Morón (Province of Buenos Aires) and Río Cuarto (Province of Córdoba), Argentina. Parents and physicians were asked to fill out a questionnaire, providing information on age, sex, signs and symptoms, treatment, hospitalization and duration of illness of each patient.

Bacteriological procedures and analysis of virulence genes. Swabs from stools were plated onto MacConkey agar plates and incubated overnight at $37{ }^{\circ} \mathrm{C}$. An aliquot of confluent growth of each sample was inoculated into $30 \mathrm{ml}$ Luria-Bertani broth, incubated with shaking at $37{ }^{\circ} \mathrm{C}$ for $4 \mathrm{~h}$ and processed for DNA extraction as described previously (Sanz et al., 1998). In a first screening, virulence genes $\left(v t_{1}, v t_{2}, e a e, e h x A\right.$ and $\left.s a a\right)$ were detected by means of a multiplex PCR, using primers and conditions described by Paton \& Paton (2002). The E. coli strains used as positive controls were: EDL $933\left(v t_{1}, v t_{2}\right.$, eae, ehxA; kindly supplied by Dr J. Blanco, Laboratorio de Referencia de E. coli, Spain) and HT 1-6 ( $v t_{1}, v t_{2}, e h x A$, saa; Krüger et al., 2006). Amplification products were analysed by 'submarine' gel electrophoresis (1.5\% agarose) and UV transillumination.

One millilitre from each $v t^{+}$culture was kept frozen at $-70{ }^{\circ} \mathrm{C}$ after the addition of $20 \%$ glycerol for further isolation of individual $v t^{+}$ colonies on a MacConkey agar plate.

Isolation of $0157 \mathrm{E}$. coli and non-0157 strains. Individual colonies were assessed to determine O157 and non-O157 serogroups. Samples positive for the $v t_{1}$ or $v t_{2}$ gene and eae gene were analysed by PCR for the presence of the eae- $\gamma$ gene, which is characteristic of, although not exclusive to, the O157 serogroup. E. coli EDL 933 was used as a positive control. The reaction mixture and temperature profile for PCR amplification were as indicated by Gannon et al. (1993).

Following individual O157 strain isolation, those samples positive for the $e a e-\gamma$ gene were subjected to immunomagnetic separation (IMS), a rapid method used for detecting 0157 strains. The methods described by Padola et al. (2004) were followed. Samples were inoculated in peptone water supplemented with antibiotics $(0.05 \mathrm{mg}$ cefixime $1^{-1}, 8 \mathrm{mg}$ vancomycin $1^{-1}, 10 \mathrm{mg}$ cefsulodin $\mathrm{l}^{-1}$ ) and incubated with shaking at $37^{\circ} \mathrm{C}$ for $6 \mathrm{~h}$. One millilitre of each sample was then subjected to IMS with polystyrene magnetic beads coated with antibody specific for O157 (Dynal) as described by Lindqvist et al. (1998). The concentrated samples were inoculated onto MacConkey sorbitol agar plates, supplemented with $2.5 \mathrm{mg}$ potassium tellurite $1^{-1}$ and $0.05 \mathrm{mg}$ cefixime $1^{-1}$ as described by Blanco et al. (1996). Separate colonies were processed for amplification of $v t_{1}$, $v t_{2}$, eae, ehxA and saa (Paton \& Paton, 2002).

Following individual non-O157 strain isolation, 500-1000 colonies of samples negative for the $e a e-\gamma$ gene and samples positive for the eae- $\gamma$ gene but unable to be isolated by means of IMS were subjected to PCR amplification of $v t_{1}, v t_{2}, e a e, e h x A$ and saa (Paton \& Paton, 2002).

Confirmation of E. coli. Micro-organisms were confirmed as E. coli by identification of the uspA gene by PCR (Chen \& Griffiths, 1998).

Serotyping. Identification of somatic $(\mathrm{O})$ and flagellum $(\mathrm{H})$ antigens was performed by agglutination with specific antisera, as described by Blanco et al. (1992). O antisera were obtained from the E. coli Reference Laboratory (Lugo, Spain), whilst $\mathrm{H}$ antisera were obtained from the Statens Serum Institut (Copenhagen, Denmark) (Orskov \& Orskov, 1984; Pradel et al., 2000).

Antimicrobial susceptibility test. Antimicrobial drug susceptibility testing was carried out using standard methods (disc diffusion test) using Mueller-Hinton agar and interpreted according to the Clinical and Laboratory Standards Institute guidelines (CLSI, 2008). VTEC strains were examined for susceptibility to cephalothin, amoxicillin/ clavulanic acid, ampicillin, cefotaxime, chloramphenicol, ciprofloxacin, gentamicin, imipenem, streptomycin, sulfonamide, tetracycline and trimethoprim/sulfamethoxazole. Inhibition zones were classified as sensitive, intermediate (moderately sensitive) or resistant according to the procedures of the CLSI (2008). Isolates exhibiting resistance to at least two of the antimicrobial agents tested were considered to be multiresistant strains. E. coli ATCC 25922 and ATCC 35218 were used as quality-control strains to monitor the accuracy of the disc diffusion test (Bauer et al., 1966; CLSI, 2008). 
Cytotoxicity assay. VT production was confirmed by a cytotoxicity assay on Vero cell monolayers according to the protocol described by Blanco et al. (1997).

Data analysis. Data were analysed using Epi Info version $6.04 \mathrm{~d}$ (Centers for Disease Control and Prevention, Atlanta, USA, and World Health Organization, Geneva, Switzerland, 2001). Descriptive statistics were used for data analysis. Associations between qualitative variables were evaluated by a $\chi^{2}$ test or Fisher's exact test (Conover, 1971).

Ethical considerations. Recommendations established in the Declaration of Helsinki for Biomedical Research Involving Human Subjects, adopted by the 18th World Medical Assembly (Helsinki, Finland, 1964) and revised by the World Medical Assembly in Tokyo (1975), Venice (1983), Hong Kong (1989), Somerset West (1996), Edinburgh (2000), Washington (2002), Tokyo (2004) and Seoul (2008), were followed.

\section{RESULTS AND DISCUSSION}

\section{All samples}

Unlike other studies conducted in our country, children $(n=437)$ with different types of diarrhoea were sampled, and a large percentage of these samples were non-bloody. A description of the physical appearance of all collected samples is shown in Fig. 1. The signs and symptoms of all of the patients studied are shown in Table 1 . The median age of the patients was 18 months (range 1-75 months). Two hundred and fifty-eight of the 437 patients (59.0\%) were children younger than 2 years old and $237(54.2 \%)$ of them were male. Eighty-four $(19.2 \%)$ of the 437 patients received antimicrobial therapy. We found a positive association between antimicrobial therapy and HUS development $(P=0.01)$.

\section{HUS $^{+}$patients}

Thirty-five ( $8.0 \%)$ of all of the patients studied developed HUS. A description of the physical appearance of the stool samples belonging to the $\mathrm{HUS}^{+}$patients is given in Fig. 1 . Watery diarrhoea without blood developed in nearly onequarter of $\mathrm{HUS}^{+}$patients, similar to the results found by Giugno et al. (2007) in Argentina (25.8\%). Diarrhoea with blood developed in $65.7 \%$ of cases, similar to the findings of Gerber et al. (2002) in Germany and Austria (57\%) and Espié et al. (2008) in France (59.4\%). The signs and symptoms of the HUS ${ }^{+}$patients are shown in Table 1 . The median age was 22 months (range 6-70 months). Eighteen of the $35 \mathrm{HUS}^{+}$patients $(51.4 \%)$ were children younger than 2 years old and 19 (54.3\%) were male. We found no significant differences between the occurrence of HUS in boys and girls $(P=0.98)$, in agreement with other studies performed in our country (Rivas et al., 2006; Giugno et al., 2007). Additionally, $13(37.1 \%)$ of the $35 \mathrm{HUS}^{+}$patients received antimicrobial therapy. Similar results have been reported in other studies. Giugno et al. (2007) reported that between 1999 and 2001, in Argentina, on average $44 \%$ of patients with HUS were treated with antimicrobial drugs. In a study conducted by Banatvala et al. (2001) in the USA, $31 \%$ of HUS patients had been treated. All patients with HUS were hospitalized and two of the $35(5.7 \%)$ died. The mortality rate was higher than that reported previously by Espie et al. (2008) in France (1\%), Gerber et al. (2002) in Germany and Austria (2\%), and Rivas et al. (2006) in Argentina (3.4\%).

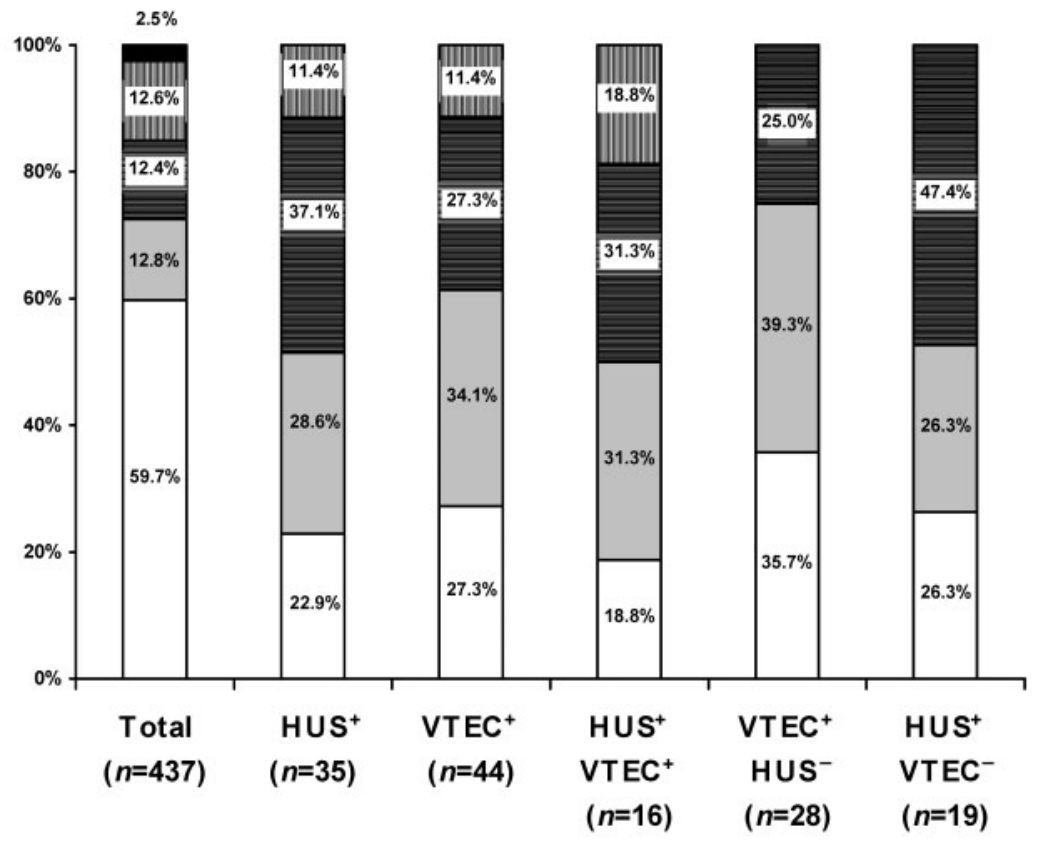

Watery without blood Not specified
Fig. 1. Bar diagram giving details of the physical appearance of stool samples from total, $\mathrm{HUS}^{+}, \mathrm{VTEC}^{+}, \mathrm{HUS}^{+} \mathrm{VTEC}^{+}, \mathrm{VTEC}^{+}$ $\mathrm{HUS}^{-}$and $\mathrm{HU}^{+}$VTEC $^{-}$patients. 
Table 1. Signs and symptoms expressed in percentages (frequencies) from all, HUS ${ }^{+}, \mathrm{VTEC}^{+}, \mathrm{HUS}^{+} \mathrm{VTEC}^{+}, \mathrm{VTEC}^{+} \mathrm{HUS}^{-}$and $\mathrm{HUS}^{+}$VTEC $^{-}$patients

The results were calculated according to the information that was available from the patient questionnaires; not all information was available for each patient.

\begin{tabular}{|c|c|c|c|c|c|c|}
\hline Symptom & All patients & HUS $^{+}$ & VTEC $^{+}$ & HUS $^{+}$VTEC $^{+}$ & VTEC $^{+}$HUS $^{-}$ & HUS $^{+}$VTEC $^{-}$ \\
\hline Vomiting & $54.5(218 / 400)$ & $75.0(24 / 32)$ & $59(23 / 39)$ & $64.3(9 / 14)$ & $56.0(14 / 25)$ & $83.3(15 / 18)$ \\
\hline Abdominal pain & $61.9(237 / 383)$ & $81.8(27 / 33)$ & $68.4(26 / 38)$ & $80.0(12 / 15)$ & $60.9(14 / 23)$ & $83.3(15 / 18)$ \\
\hline Fever & $50.4(201 / 399)$ & $54.5(18 / 33)$ & $41.0(16 / 39)$ & $53.3(8 / 15)$ & $33.3(8 / 24)$ & $55.6(10 / 18)$ \\
\hline Anuria & $4.5(11 / 244)$ & $83.3(10 / 12)$ & $26.3(5 / 19)$ & $83.3(5 / 6)$ & $0.0(0 / 13)$ & $83.3(5 / 6)$ \\
\hline Oliguria & $7.9(27 / 342)$ & $91.7(22 / 24)$ & $32.4(11 / 34)$ & $100.0(11 / 11)$ & $0.0(0 / 13)$ & $84.6(11 / 13)$ \\
\hline Sensory alteration & $2.5(6 / 239)$ & $27.3(3 / 11)$ & $15.8(3 / 19)$ & $50.0(3 / 6)$ & $0.0(0 / 13)$ & $0.0(0 / 5)$ \\
\hline Weakness & $6.3(15 / 240)$ & $18.2(2 / 11)$ & $15.8(3 / 19)$ & $33.0(2 / 6)$ & $7.7(1 / 13)$ & $0.0(0 / 5)$ \\
\hline Paleness & $6.7(16 / 239)$ & $63.6(7 / 11)$ & $15.8(3 / 19)$ & $50.0(3 / 6)$ & $0.0(0 / 13)$ & $80.0(4 / 5)$ \\
\hline Neurological compromise & $1.8(6 / 337)$ & $18.2(2 / 11)$ & $7.1(2 / 28)$ & $40.0(2 / 5)$ & $0.0(0 / 23)$ & $0.0(0 / 6)$ \\
\hline HUS & $8.1(35 / 434)$ & $100.0(35 / 35)$ & $36.4(16 / 44)$ & $100.0(16 / 16)$ & $0.0(0 / 28)$ & $100.0(19 / 19)$ \\
\hline Total $(n)$ & 437 & 35 & 44 & 16 & 28 & 19 \\
\hline
\end{tabular}

\section{VTEC $^{+}$patients}

Forty-four of our patients were positive for VTEC. The frequency and characteristics of VTEC infections in children with different types of diarrhoea in our country are not well established. López et al. (1998) found evidence of VTEC infection (by using a free faecal cytotoxin assay, PCR and/or DNA probes) in $57 \%$ of HUS patients, $38 \%$ of patients with diarrhoea with blood, $21 \%$ of patients with watery diarrhoea without blood and none of the healthy patients. In this work, we studied patients who, in nearly $60 \%$ of the cases, presented watery diarrhoea without blood. VTEC was found in $10.1 \%$ of all stool specimens analysed and in $45.7 \%$ of stool cultures from patients with HUS, with bloody and non-bloody diarrhoea. The physical appearance of stool samples of $\mathrm{VTEC}^{+}$patients is shown in Fig. 1. The signs and symptoms of these patients are shown in Table 1 . Their median age was 21.5 months (range 6-72 months). It is interesting that, in nearly $30 \%$ of the VTEC $^{+}$samples, faeces were watery. Twenty-five of the 44 $\mathrm{VTEC}^{+}$patients $(56.8 \%)$ were children under 2 years old and $20(45.5 \%)$ were male. Fourteen $(31.8 \%)$ of the 44 $\mathrm{VTEC}^{+}$patients received antimicrobial therapy. We could establish a positive association between HUS development and antibiotic therapy for the patients with evidence of VTEC infection $(P=0.03)$.

\section{HUS $^{+}$VTEC $^{+}$patients}

Infection with VTEC was diagnosed in 16 of the $35 \mathrm{HUS}^{+}$ patients $(45.7 \%)$, results similar to other studies carried out in Argentina (32.8, 57 and 59.1\%) but lower than those described in Germany and Austria (83\%), France (86\%, 66\%) and the USA (72\%) (López et al., 1998; Banatvala et al., 2001; Gerber et al., 2002; Rivas et al., 2006, 2008; Espié et al., 2008). These differences may reflect regional variations, or may be because the identification of specific antibodies or free faecal toxin was not performed, but instead PCR was used to determine VTEC infection.
The physical appearance of the stool samples of the HUS ${ }^{+}$ VTEC $^{+}$patients is shown in Fig. 1. It should be noted that, in nearly $20 \%$ of HUS cases positive for VTEC, the stools were non-bloody. The signs and symptoms of the HUS ${ }^{+}$ VTEC $^{+}$patients are shown in Table 1 . The median age of the $\mathrm{HUS}^{+}$VTEC $^{+}$patients was 23 months (range 6-60 months). Nine of the $16 \mathrm{HUS}^{+} \mathrm{VTEC}^{+}$patients $(56.3 \%)$ were children under 2 years old, and eight (50\%) were male. Seven $(43.8 \%)$ of the 16 HUS $^{+}$VTEC $^{+}$patients received antimicrobial therapy. All patients with HUS and with evidence of VTEC infection were hospitalized and one of the $16(6.3 \%)$ died.

\section{VTEC $^{+}$HUS $^{-}$patients}

The physical appearance of the stool samples of the VTEC $^{+}$patients without HUS $(n=28)$ is shown in Fig. 1 . Although the differences were not significant $(P=0.68)$, this group presented more watery diarrhoea without blood than the $\mathrm{HUS}^{+} \mathrm{VTEC}^{+}$patients. The signs and symptoms of these patients are shown in Table 1. The occurrence of vomiting, fever and abdominal pain was more common in the $\mathrm{HUS}^{+} \mathrm{VTEC}^{+}$group than in the $\mathrm{VTEC}^{+} \mathrm{HUS}^{-}$ group, similar to results reported by Oshima (1997), although the differences were not statistically significant ( $P=0.61, P=0.21$ and $P=0.29$, respectively). The median age of the $\mathrm{VTEC}^{+} \mathrm{HUS}^{-}$patients was 17 months (range 772 months). Sixteen of the $28 \mathrm{VTEC}^{+} \mathrm{HUS}^{-}$patients $(57.14 \%)$ were children under 2 years old, and 12 $(42.85 \%)$ were male.

\section{HUS $^{+}$VTEC $^{-}$patients}

Nineteen of the $\mathrm{HUS}^{+}$patients (54.3\%) showed no evidence of VTEC infection. The physical appearance of the stool samples of the HUS ${ }^{+}$VTEC $^{-}$patients is shown in Fig. 1, and their signs and symptoms in Table 1. This group presented no neurological complications (sensory 
alteration, weakness or neurological damage) and had more vomiting and slightly more fever and abdominal pain than the $\mathrm{HUS}^{+}$VTEC $^{+}$patients. The median age of the $\mathrm{HUS}^{+}$VTEC $^{-}$patients was 21 months (range 8-70 months). Nine of the $19 \mathrm{HUS}^{+}$VTEC $^{-}$patients $(47.37 \%)$ were children under 2 years old, and 11 $(57.89 \%)$ were male. No association was found between HUS development and antibiotic therapy for the patients who showed no evidence of VTEC infection $(P=0.5)$. All patients with HUS and without evidence of VTEC infection were hospitalized and one of the 19 (5.26\%) died. There was no difference between the mortality rate of $\mathrm{HUS}^{+}$ VTEC $^{+}$patients and HUS ${ }^{+}$VTEC $^{-}$patients $(P=1)$.

\section{Individual strain isolation}

Similar to results from other studies, we isolated individual strains from $34(77.3 \%)$ of the $44 \mathrm{VTEC}^{+}$samples. Paton et al. (1996), Piérard et al. (1997), Blanco et al. (2004) and Espié et al. (2008), using a protocol similar to the present one, were unable to isolate VTEC colonies in 24, 19, 13 and $16 \%$ of PCR-positive stools, respectively. This could be explained by the high sensitivity of the PCR technique, which detects a positive result when a VTEC colony is mixed with commensal $E$. coli even at a ratio as low as $1: 10^{-4}$ or $1: 10^{-8}$.

\section{Strain characterization}

A number of VTEC serotypes and genotypes were characterized and the results are shown in Table 2. As in other studies conducted in Argentina, the USA, France, Belgium, Germany and Austria, O157: H7 was the serotype found most frequently in stool cultures from paediatric patients with HUS, and VTEC could be isolated and characterized in $92.3 \%$ of samples (Piérard et al., 1997; Banatvala et al., 2001; Gerber et al., 2002; Rivas et al., 2006, 2008; Giugno et al., 2007; Espié et al., 2008). In addition, in the current work, an $\mathrm{O} 145: \mathrm{H}^{-}$strain was isolated from an HUS patient. Rivas et al. (2006) characterized 48 VTEC strains recovered from bloody and non-bloody stools from

Table 2. Serotypes and virulence genotypes of the 34 VTEC strains

\begin{tabular}{|llcc|}
\hline Serotype & $\begin{array}{c}\text { Virulence } \\
\text { genotype }\end{array}$ & $\begin{array}{c}\text { No. of } \\
\text { isolates }\end{array}$ & Percentage \\
\hline O157: $\mathrm{H} 7$ & $v t_{2}$, eae, ehxA & 20 & 58.8 \\
$0145: \mathrm{NM}$ & $v t_{2}$, eae, ehxA & 6 & 17.7 \\
$\mathrm{O} 26: \mathrm{H} 11$ & $v t_{1}$, eae, ehxA & 2 & 5.9 \\
$\mathrm{O} 121: \mathrm{H} 19$ & $v t_{2}$, eae, ehxA & 2 & 5.9 \\
$\mathrm{O} 111: \mathrm{H} 2$ & $v t_{1}$, eae, ehxA & 1 & 2.9 \\
$\mathrm{O} 118: \mathrm{H} 2$ & $v t_{1}$, eae, ehxA & 1 & 2.9 \\
$\mathrm{O} ?: \mathrm{H} ?$ & $v t_{2}$, eae, ehxA & 1 & 2.9 \\
$\mathrm{O} ?: \mathrm{H} ?$ & $v t_{1}, v t_{2}$, ehxA & 1 & 2.9 \\
Total & & 34 & 100.0 \\
\hline
\end{tabular}

patients with diarrhoea and HUS contacts. Of these, $81.2 \%$ were E. coli $\mathrm{O} 157: \mathrm{H} 7$ and the remainder were VTEC nonO157:H7. Unlike in the study of Rivas et al. (2006), the presence of the O157:H7 serotype was found in only $38.1 \%$ of the stool samples from patients without HUS in our study. These differences could be due to our sampling of children with different types of diarrhoea, rather than being oriented towards the study of bloody diarrhoea or to children in contact with HUS patients. Remarkably, López et al. (1998) found that the incidence of O157: H7 was only $2-18 \%$ for HUS patients and $3 \%$ in the case of the bloody diarrhoea group. In Australia, most of the non-O157:H7 VTEC serotypes (mainly $\mathrm{O} 111: \mathrm{H}^{-}$) were found in sporadic HUS cases, and these serotypes were also associated with outbreaks (Goldwater \& Bettelheim, 1998; Elliott et al., 2001).

Unlike the findings of researchers from other countries, our strains corresponding to serotype O157:H7 possessed the $v t_{2}$ gene only and all of them were motile. In the USA, Slutsker et al. (1997) found that $86.4 \%$ of O157: H7 strains produced $v t_{1}$ and $v t_{2}, 11.9 \%$ produced $v t_{2}$ only and $1.7 \%$ produced $v t_{1}$ only. They also found E. coli O157 isolates that were non-motile (Slutsker et al., 1997). In contrast, Willshaw et al. (2001) found that $76 \%$ of the O157: H7 isolates in England and Wales carried the $v t_{2}$ gene only, $23.3 \%$ encoded both $v t_{1}$ and $v t_{2}$, and $v t_{1}$-only strains were very rare. The strains either possessed the flagellar antigen $\mathrm{H} 7$ or were non-motile. In two different studies conducted by Piérard et al. (1997) and Klein et al. (2002), all O157: H7 isolates possessed the $v t_{2}$ gene in combination with $v t_{1}$ in 31 and $71 \%$ of cases, respectively. Non-motile strains were also found by Piérard et al. (1997).

Almost all of the strains isolated in the present work were positive for the eae and ehxA genes, which coincides with the group of strains that are more frequently associated with severe disease, HUS and young age, as described by Beutin et al. (1998). López et al. (1998) also found a positive association between the presence of the eae and ehxA genes and HUS development.

\section{Antimicrobial resistance}

In the present study, most of the isolates were sensitive to all of the antimicrobials tested. The percentages of VTEC isolates that exhibited a sensitive, intermediate or resistant phenotype with respect to each antimicrobial agent are shown in Table 3. Five $(14.7 \%)$ of the 34 isolates were resistant to at least one antimicrobial agent. Of these five isolates, four were resistant to only one antimicrobial agent. There was one O157:H7 strain resistant to amoxicillin/clavulanic acid, and two $\mathrm{O} 145: \mathrm{H}^{-}$and one O157:H7 resistant to cephalotin. Three of these four strains belonged to HUS cases, and the other was an O145: $\mathrm{H}^{-}$strain isolated from a bloody and mucous stool. The multiresistant strain corresponded to an E. coli O157: H7, isolated from a 9-month-old male HUS patient from the city of Bahía Blanca. He did not receive 
Table 3. Percentages of VTEC strain isolates showing a sensitive (S), intermediate (I) or resistant (R) phenotype with respect to antimicrobial agents, as determined by the agar disc diffusion method

\begin{tabular}{|lccc|}
\hline Antimicrobial agent & S (\%) & I (\%) & R (\%) \\
\hline Amoxicillin/clavulanic acid & 94.1 & 0 & 5.9 \\
Ampicillin & 97.05 & 2.95 & 0 \\
Cefotaxime & 100 & 0 & 0 \\
Cephalotin & 50 & 41.15 & 8.85 \\
Chloramphenicol & 97.05 & 2.95 & 0 \\
Ciprofloxacin & 100 & 0 & 0 \\
Gentamicin & 100 & 0 & 0 \\
Imipenem & 100 & 0 & 0 \\
Streptomycin & 100 & 0 & 0 \\
Sulfonamide & 97.05 & 0 & 2.95 \\
Tetracycline & 97.05 & 0 & 2.95 \\
Trimethoprim/sulfamethoxazole & 97.05 & 2.95 & 0 \\
\hline
\end{tabular}

antimicrobial therapy. The strain showed resistance to amoxicillin/clavulanic acid, tetracycline and sulfonamide. Similarly, Slutsker et al. (1997) found antibiotic resistance in $8.5 \%$ of the $\mathrm{O} 157: \mathrm{H} 7$ strains studied. The resistance observed by these authors was to ampicillin, tetracycline, streptomycin, sulfisoxazole, chloramphenicol, gentamicin and trimethoprim/sulfamethoxazole. However, Willshaw et al. (2001) found a mean of $20 \%$ of O157:H7 strains resistant to one or more antimicrobial tested. The resistance was observed to streptomycin, sulfonamide and tetracycline.

Despite most of the strains being sensitive to all of the antimicrobials tested, a positive association between HUS and antibiotic therapy, both for the total number of patients studied and for the $\mathrm{VTEC}^{+}$group, was observed in the present work. These results agree with the hypothesis of Wong et al. (2000), who suggested that antibiotic treatment of children with E. coli O157:H7 infection increases the risk of HUS. This could perhaps be due to other VTEC, as in the present work, where one patient with $\mathrm{O} 145: \mathrm{H}^{-}$infection was treated with antibiotics and developed HUS.

\section{VT production}

All of the VTEC isolates produced a cytopathic effect on Vero cell monolayers.

\section{Clinical findings related to serotype}

Twelve out of $20 \mathrm{O} 157: \mathrm{H7}$ strains $(60.0 \%)$ were isolated from stools corresponding to HUS patients. However, only one $\mathrm{O} 145: \mathrm{H}^{-}$of the 14 non-O157: $\mathrm{H} 7$ strains $(7.1 \%)$ was recovered from an HUS patient. In contrast to our results, Klein et al. (2002) observed HUS development in $18 \%$ of patients with $\mathrm{O} 157: \mathrm{H} 7$ and none in patients with nonO157: H7 VTEC infection. In addition, Wong et al. (2000) and Tarr et al. (2005) observed HUS development in 14 and $15 \%$ of patients with O157:H7 VTEC infection, respectively. The results of the present study were quite different: we found HUS development in 60 and $7.1 \%$ of patients with O157:H7 and non-O157:H7 infection, respectively. The relatively high frequency of HUS may be due to the fact that samples were from children under 75 months, who are supposed to have a higher risk of developing HUS once infected by VTEC than older children or adults (Goldwater, 2007).

We found a positive association between the O157: $\mathrm{H} 7$ serotype and HUS development $(P=0.001)$, as well as with higher hospitalization rates $(P=0.004)$ and abdominal pain $(P=0.01)$ (Table 4). Moreover, $81.3 \%$ of the O157:H7 isolates were from children with bloody diarrhoea, whereas $53.8 \%$ of the non-O157:H7 strains were isolated from bloody stools. These results are similar to those found by Gerber et al. (2002) and Klein et al. (2002). It could be that O157:H7 is associated with more severe disease and HUS because all of the strains contained $v t_{2}$ only, which is more virulent than $v t_{1}$ alone or the combination of $v t_{1}$ and $v t_{2}$ (Proulx et al., 2001; Tarr et al., 2005). Non-O157:H7 serotypes were found more frequently in children under 2 years old $(57.1 \%)$, and $\mathrm{O} 157: \mathrm{H} 7$ serotypes were found equally in both groups ( $50.0 \%$ each), which agree with the results obtained by Beutin et al. (1998) in Germany and Gerber et al. (2002) in Germany and Austria.

Although O157:H7 VTEC $^{+}$patients presented higher rates of hospitalization and HUS, we believe that all of the strains analysed carried a virulence genotype capable of causing severe disease. Furthermore, all of the VTEC isolates produced a cytopathic effect on Vero cell monolayers, confirming their ability to express VT. Most of the non-O157:H7 serotypes that we found have been described previously in human disease and were associated with HUS (Griffin \& Tauxe, 1991; Goldwater \& Bettelheim, 1998; Gerber et al., 2002; Johnson et al., 2006).

\section{Conclusions}

In conclusion, the data obtained in this study further our current knowledge on the role and clinical course of VTEC

Table 4. HUS development, hospitalization and abdominal pain in patients infected with $0157: \mathrm{H} 7$ and non-O157:H7 serotypes

\begin{tabular}{|lcccc|}
\hline Variable & Category & O157:H7 & $\begin{array}{c}\text { Non- } \\
\text { O157: H7 }\end{array}$ & P value \\
\hline HUS & Yes & 12 & 1 & 0.001 \\
Hospitalization & No & 8 & 13 & \\
& Yes & 15 & 2 & 0.004 \\
Abdominal pain & No & 4 & 11 & \\
& Yes & 14 & 4 & 0.01 \\
& No & 3 & 8 & \\
\hline
\end{tabular}


infections in childhood acute diarrhoea and may be useful for the prevention and diagnosis and early management of this disease. The present data increase the evidence that VTEC is present in bloody and non-bloody stools from children with acute diarrhoea with and without HUS. We found a large variety of VTEC strains belonging to different serotypes and presenting different virulence genotypes capable of causing severe disease. It is necessary to improve the detection and isolation of VTEC in cases of acute diarrhoea. Children with evidence of VTEC infection should be monitored carefully in a hospital and treated to prevent the onset or progression of HUS. Early diagnosis of infection should help in making clinical decisions regarding the administration of fluids and antibiotics. These interventions should be helpful in reducing morbidity and mortality associated with the disease. Finally, rapid diagnosis can serve to limit the spread to contacts and allow public health authorities the timely detection of new cases of VTEC and of contamination sources. Detection of VTEC infection should be carried out at least in paediatric patients with bloody diarrhoea and/or HUS, who are at greater risk of developing severe disease when infected with these pathogens. A rapid, sensitive, accurate and non-expensive diagnostic method should be incorporated into clinical laboratory protocols. As many VTEC serotypes can cause severe disease, the diagnosis should be independent of serotype. It is possible that the optimal approach to VTEC diagnosis could be by multiplex PCR analysis for the presence of $v t_{1}, v t_{2}$, eae and ehxA genes, which are present in most of the VTEC strains isolated from HUS patients.

\section{ACKNOWLEDGEMENTS}

The authors are greatly thankful to 'Sociedad Argentina de Pediatría', Hospital 'Ramón Santamarina', Laboratorio 'Pérez Cambet', 'Nueva Clínica Chacabuco', Municipalidad de Bahía Blanca, Hospital 'Dr José Penna', Hospital 'Alejandro Posadas' and Nuevo Hospital de Río Cuarto 'San Antonio de Padua' for their collaboration in sample collections. We also thank María R. Ortiz, Marcelo E. Sanz, Hilda Etchevarría and Guillermo H. Arroyo for their technical assistance. M.A.R. is a holder of a fellowship from the National Council of Scientific and Technical Research (CONICET). A.E.P. is a member of the Scientific Research Commission of the Province of Buenos Aires (CICPBA). This work was partly supported with grants from CICPBA, CONICET, Fundación Alberto J. Roemmers and the Fund for Scientific and Technological Research (FONCYT).

\section{REFERENCES}

Banatvala, N., Griffin, P. M., Greene, K. D., Barrett, T. J., Bibb, W. F., Green, J. H., Wells, J. G. \& Hemolytic Uremic Syndrome Study Collaborators (2001). The United States National Prospective Hemolytic Uremic Syndrome Study: microbiologic, serologic, clinical, and epidemiologic findings. J Infect Dis 183, 1063-1070.

Bauer, A. W., Kirby, W. M. M., Sherris, J. C. \& Turck, M. (1966). Antibiotic susceptibility testing by a standardized single disk method. Am J Clin Pathol 45, 493-496.
Beutin, L., Zimmermann, S. \& Gleier, K. (1998). Human infections with Shiga toxin-producing Escherichia coli other than serogroup O157 in Germany. Emerg Infect Dis 4, 635-639.

Blanco, J., Blanco, M., Alonso, M. P., Blanco, J. E., Garabal, J. I. \& González, E. A. (1992). Serogroups of Escherichia coli strains producing cytotoxic necrotizing factors CNF1 and CNF2. FEMS Microbiol Lett 75, 155-159.

Blanco, J. E., Blanco, M., Mora, A., Prado, C., Río, M., Fernández, L., Fernández, M. J., Saínz, V. \& Blanco, J. (1996). Detection of enterohaemorrhagic Escherichia coli O157:H7 in ground beef using immunomagnetic separation. Microbiologia 12, 385-394.

Blanco, M., Blanco, J. E., Blanco, J., Mora, A., Prado, C., Alonso, M. P., Mouriño, M., Madrid, C., Balsalobre, C. \& other authors (1997). Distribution and characterization of fecal verotoxin-producing Escherichia coli (VTEC) isolated from healthy cattle. Comparison with VTEC obtained from calves with diarrhea. Vet Microbiol 54, 309-319.

Blanco, J. E., Blanco, M., Alonso, M. P., Mora, A., Dahbi, G., Coira, M. A. \& Blanco, J. (2004). Serotypes, virulence genes, and intimin types of Shiga toxin (verotoxin)-producing Escherichia coli isolates from human patients: prevalence in Lugo, Spain, from 1992 through 1999. J Clin Microbiol 42, 311-319.

Chen, J. \& Griffiths, M. W. (1998). PCR differentiation of Escherichia coli from other Gram-negative bacteria using primers derived from the nucleotide sequences flanking the gene encoding the universal stress protein. Lett Appl Microbiol 27, 369-371.

CLSI (2008). Performance Standards for Antimicrobial Susceptibility Testing, 18th Informational Supplement. M100-S18. Wayne, PA: Clinical and Laboratory Standards Institute.

Conover, W. J. (1971). Practical Nonparametric Statistics. New York: Wiley.

Elliott, E. J., Robins-Browne, R. M., O'Loughlin, E. V., Bennett-Wood, V., Bourke, J., Henning, P., Hogg, G. G., Knight, J., Powell, H. \& other authors (2001). Nationwide study of haemolytic uraemic syndrome: clinical, microbiological, and epidemiological features. Arch Dis Child 85, 125-131.

Espié, E., Grimont, F., Mariani-Kurkdjian, P., Bouvet, P., Haeghebaert, S., Filliol, I., Loirat, C., Decludt, B., Nhu Tran Minh, N. \& other authors (2008). Surveillance of hemolytic uremic syndrome in children less than 15 years of age, a system to monitor O157 and nonO157 Shiga toxin-producing Escherichia coli infections in France, 19962000. Pediatr Infect Dis J 27, 595-601.

Gannon, V. P. J., Rashed, M., King, R. K. \& Golsteyn Thomas, E. J. (1993). Detection and characterization of the eae gene of Shiga-like toxin-producing Escherichia coli using polymerase chain reaction. J Clin Microbiol 31, 1268-1274.

Gerber, A., Karch, H., Allerberg, F., Verweyen, M. \& Zimmerhackl, L. B. (2002). Clinical course and the role of Shiga toxin-producing Escherichia coli infection in the hemolytic-uremic syndrome in pediatric patients, 1997-2000, in Germany and Austria: a prospective study. J Infect Dis 186, 493-500.

Giugno, S. M., Bibiloni, N., Rahman, R., Miliwebsky, E., Chinen, I. \& Rivas, M. (2007). Association between uremic hemolytic syndrome and infection by Shiga toxin-producing Escherichia coli. Acta Bioquím Clín Latinoam 41, 27-33 (in Spanish).

Goldwater, P. N. (2007). Treatment and prevention of enterohemorrhagic Escherichia coli infection and hemolytic uremic syndrome. Expert Rev Anti Infect Ther 5, 653-663.

Goldwater, P. N. \& Bettelheim, K. A. (1998). New perspectives on the role of Escherichia coli $\mathrm{O} 157: \mathrm{H} 7$ and other enterohaemorrhagic E. coli serotypes in human disease. J Med Microbiol 47, 1039-1045. 
Griffin, P. M. \& Tauxe, R. V. (1991). The epidemiology of infections caused by Escherichia coli O157: H7, other enterohemorrhagic E. coli, and the associated hemolytic uremic syndrome. Epidemiol Rev 13, 60-98.

Johnson, K. E., Thorpe, C. M. \& Sears, C. L. (2006). The emerging clinical importance of non-O157 Shiga toxin-producing Escherichia coli. Clin Infect Dis 43, 1587-1595.

Karch, H., Tarr, P. I. \& Bielaszewska, M. (2005). Enterohaemorrhagic Escherichia coli in human medicine. Int J Med Microbiol 295, 405-418.

Karmali, M. A. (1989). Infection by verocytotoxin-producing Escherichia coli. Clin Microbiol Rev 2, 15-38.

Klein, E. J., Stapp, J. R., Clausen, C. R., Boster, D. R., Wells, J. G., Qin, X., Swerdlow, D. L. \& Tarr, P. I. (2002). Shiga toxin-producing Escherichia coli in children with diarrhea: a prospective point-of-care study. J Pediatr 141, 172-177.

Krüger, A., Padola, N. L., Parma, A. E. \& Lucchesi, P. M. A. (2006). Intraserotype diversity among Argentinian verocytotoxigenic Escherichia coli detected by random amplified polymorphic DNA analysis. J Med Microbiol 55, 545-549.

Lindqvist, R., Antonsson, A. K., Norling, B., Persson, L., Ekström, C. L., Fäger, U., Eriksson, E., Lofdahl, S. \& Norberg, P. (1998). The prevalence of verocytotoxin-producing Escherichia coli (VTEC) and E. coli O157: H7 in beef in Sweden determined by PCR assays and an immuno-magnetic separation (IMS) method. Food Microbiol 15, 591601.

López, E. L., Contrini, M. M. \& De Rosa, M. F. (1998). Epidemiology of Shiga toxin-producing E. coli in South America. In Escherichia coli O157: H7 and Other Shiga Toxin-Producing E. coli Strains, pp. 30-37. Edited by J. B. Kaper \& A. D. O’Brien. Washington, DC: American Society for Microbiology.

Orskov, F. \& Orskov, I. (1984). Serotyping of Escherichia coli. Methods Microbiol 114, 43-112.

Oshima, T. (1997). Predictive factors for development of hemolytic uremic syndrome (HUS) and early intensive treatments for prevention of HUS enterohemorrhagic Escherichia coli infection. Jpn J Antibiot 50, 855-861.

Padola, N. L., Sanz, M. E., Blanco, J. E., Blanco, M., Blanco, J., Etcheverría, A. I., Arroyo, G. H., Usera, M. A. \& Parma, A. E. (2004). Serotypes and virulence genes of Shigatoxigenic Escherichia coli (STEC) isolated from a feedlot in Argentina. Vet Microbiol 100, 3-9.

Paton, A. W. \& Paton, J. C. (1998). Detection and characterization of Shiga toxigenic Escherichia coli by using multiplex PCR assays for $s t x_{1}$, stx $x_{2}$, eae, enterohemorrhagic E. coli hlyA, rfbO111, and rfbO157. J Clin Microbiol 36, 598-602.

Paton, A. W. \& Paton, J. C. (2002). Direct detection and characterization of Shiga toxigenic Escherichia coli by multiplex PCR for $s t x_{1}, s t x_{2}$, eae, ehxA, and saa. J Clin Microbiol 40, 271-274.

Paton, A. W., Ratcliff, R. M., Doyle, R. M., Seymour-Murray, J., Davos, D., Lanser, J. A. \& Paton, J. C. (1996). Molecular microbiological investigation of an outbreak of hemolytic-uremic syndrome caused by dry fermented sausage contaminated with Shiga-like toxin-producing Escherichia coli. J Clin Microbiol 34, 1622-1627.

Paton, A. W., Srimanote, P., Woodrow, M. C. \& Paton, J. C. (2001). Characterization of Saa, a novel autoagglutinating adhesin produced by locus of enterocyte effacement-negative Shiga-toxigenic Escherichia coli strains that are virulent for humans. Infect Immun 69, 6999-7009.

Piérard, D., Stevens, D., Moriau, L., Lior, H. \& Lauwers, S. (1997). Isolation and virulence factors of verocytotoxin-producing Escherichia coli in human stool samples. Clin Microbiol Infect 3, 531-540.

Pradel, N., Livrelli, V., De Champs, C., Palcoux, J.-B., Reynaud, A., Scheutz, F., Sirot, J., Joly, B. \& Forestier, C. (2000). Prevalence and characterization of Shiga toxin-producing Escherichia coli isolated from cattle, food and children during a one-year prospective study in France. J Clin Microbiol 38, 1023-1031.

Proulx, F., Seidman, E. G. \& Karpman, D. K. (2001). Pathogenesis of Shiga toxin-associated hemolytic uremic syndrome. Pediatr Res 50, 163-171.

Rivas, M., Miliwebsky, E., Chinen, I., Deza, N. \& Leotta, G. A. (2006). The epidemiology of hemolytic uremic syndrome in Argentina. Diagnosis of the etiologic agent, reservoirs and routes of transmission. Medicina (B Aires) 66 (Suppl. 3), 27-32 (in Spanish).

Rivas, M., Sosa-Estani, S., Rangel, J., Caletti, M. G., Vallés, P., Roldán, C. D., Balbi, L., Marsano de Mollar, M. C., Amoedo, D. \& other authors (2008). Risk factors for sporadic Shiga toxin-producing Escherichia coli infections in children, Argentina. Emerg Infect Dis 14, 763-771.

Rivero, M. A., Padola, N. L., Etcheverría, A. I. \& Parma, A. E. (2004). Enterohemorrhagic Escherichia coli and hemolytic-uremic syndrome in Argentina. Medicina (B Aires) 64, 352-356 (in Spanish).

Sanz, M. E., Viñas, M. R. \& Parma, A. E. (1998). Prevalence of bovine verotoxin-producing Escherichia coli in Argentina. Eur J Epidemiol 14, 399-403.

Slutsker, L., Ries, A. A., Greene, K. D., Wells, J. G., Hutwagner, L. \& Griffin, P. (1997). Escherichia coli O157:H7 diarrhea in the United States: clinical and epidemiological features. Ann Intern Med 126, 505-513.

Tarr, P. I., Gordon, C. A. \& Chandler, W. L. (2005). Shiga-toxinproducing Escherichia coli and haemolytic uraemic syndrome. Lancet 365, 1073-1086.

Voyer, L. E. (1996). Síndrome Urémico Hemolitico. Buenos Aires: Ed. López.

Willshaw, G. A., Cheasty, T., Smith, H. R., O’Brien, S. J. \& Adak, G. K. (2001). Verocytotoxin-producing Escherichia coli (VTEC) O157 and other VTEC from human infections in England and Wales: 19951998. J Med Microbiol 50, 135-142.

Wong, C. S., Jelacic, S., Habeeb, R. L., Watkins, S. L. \& Tarr, P. I. (2000). The risk of the hemolytic-uremic syndrome after antibiotic treatment of Escherichia coli O157: H7 infections. N Engl J Med 342, 1930-1936. 